\title{
The Condensation of Collagen Leads to an Extended Standing Time and a Decreased Pro-inflammatory Tissue Response to a Newly Developed Pericardium-based Barrier Membrane for Guided Bone Regeneration
}

\author{
TRISTAN GUELDENPFENNIG ${ }^{1,2^{*}}$, ALIREZA HOUSHMAND $^{1 *}$, STEVO NAJMAN $^{3}$, \\ SANJA STOJANOVIC ${ }^{3}$, TADAS KORZINSKAS ${ }^{1}$, RALF SMEETS ${ }^{1}$, MARTIN GOSAU ${ }^{1}$, \\ JENS PISSAREK ${ }^{4}$, STEFFEN EMMERT $^{5}$, OLE JUNG $^{1,5 \#}$ and MIKE BARBECK ${ }^{1,6 \#}$ \\ ${ }^{1}$ University Hospital Hamburg-Eppendorf, Hamburg, Germany; \\ ${ }^{2}$ Werner Forßmann Hospital Eberswalde, Eberswalde, Germany; \\ ${ }^{3}$ Department for Cell and Tissue Engineering Institute of Biology and Human Genetics, \\ Faculty of Medicine, University of Niš, Niš, Serbia; \\ ${ }^{4}$ Biotrics bioimplants GmbH, Berlin, Germany; \\ ${ }^{5}$ Clinic and Policlinic for Dermatology and Venereology, \\ University Medical Center Rostock, Rostock, Germany; \\ ${ }^{6}$ BerlinAnalytix GmbH, Berlin, Germany
}

\begin{abstract}
Background/Aim: A new manufacturing process has been established for the condensation of collagen derived from porcine pericardium to develop a new dental barrier membrane (CPM) that can provide a long barrier functionality. A native collagen membrane (PM) was used as control. Materials and Methods: Established in vitro procedures using L929 and MC3T3 cells were used for cytocompatibility analyses. For the in vivo study, subcutaneous implantation of both membrane types in $40 \mathrm{BALB} / \mathrm{c}$ mice and established histological, immunohistochemical and histomorphometrical methods were conducted. Results: Both the in vitro and in vivo results revealed that the CPM has a biocompatibility profile comparable to that of the control membrane. The new CPM induced a tissue reaction including more M2-macrophages. Conclusion: The CPM is fully biocompatible and seems to support the early healing process. Moreover, the new
\end{abstract}

This article is freely accessible online.

\footnotetext{
*These Authors contributed equally to this manuscript.

\#These Authors contributed equally to this manuscript.

Correspondence to: Mike Barbeck, BerlinAnalytix GmbH, Ullsteinstrasse 108, D-12109 Berlin, Germany. Tel: +49 17681022467, e-mail: mike.barbeck@icloud.com

Key Words: Collagen membrane, Guided Bone Regeneration (GBR), degradation, macrophages, pericardium.
}

biomaterial seems to prevent cell ingrowth for a longer period of time, making it ideally suited for GBR procedures.

Nowadays, Guided Bone Regeneration (GBR) can be regarded as the standard therapeutic procedure in implantology and oral and maxillofacial surgery. In this context, current systematic reviews show that the GBR technique is a reliable method, especially for horizontal and vertical bone augmentation of the edentulous alveolar ridge $(1,2)$. The principle of this method is based on the separation of regenerative cell types, such as osteoblasts, from cell types that might interrupt the bony regeneration process, such as keratinocytes, through the use of resorbable or non-resorbable barrier membranes $(3,4)$. In addition to the barrier function, membranes used for the GBR technique should have high biocompatibility, dimensional stability and easy handling (5). Although non-resorbable membranes were predominantly used when the GBR technique was first established, resorbable membranes sourced mainly from bovine and porcine collagen type I and III, are increasingly used in clinical applications (6-8). Collagen is highly biocompatible and provides regenerative properties due to its functionality as an extracellular matrix protein (9-13). For example, collagen has a chemotactic effect on fibroblasts, promoting tissue integration (9). Collagen-based barrier membranes have already been extensively investigated in both animal experiments and clinical studies (3, 14-19). Although the clinical results related to collagen-based membranes are comparable to those of non-resorbable 
membranes, their application has a lower incidence of spontaneous exposures $(20,21)$. In addition, if collagen barrier membranes become exposed during soft tissue healing, they remain infection-free $(21,22)$.

Beside their several advantages, a potential disadvantage of resorbable barrier membranes based on native collagen is their relatively short functional life-span, as collagen is rapidly degraded by tissue-specific proteases (e.g. collagenases deriving from cell types such as macrophages) (23). This is especially a problem for the augmentation of large-volume defects, where a prolonged regeneration time is required. Therefore, non-resorbable membranes are often applied for such large defect types. Different approaches have been used to address this issue of resorbable collagenbased barrier membranes, such as new cross-linking techniques $(22,24)$. However, different studies have shown a correlation between the degree of collagen cross-linking using chemical agents such as glutaraldehyde, and a reduction in biocompatibility $(25,26)$.

Other approaches to increase the functional life span of collagen membranes, is to use a combination of collagen with different materials such as synthetic polymers like polycaprolactone (PCL), or resorbable metals like magnesium $(\mathrm{Mg})(27,28)$. The combination of collagen with synthetic materials in the form of grids has been examined not only to increase the standing time of the membrane, but also to improve the volume stability. Another possibility is the condensation of collagen sourced from the pericardium. By condensing the collagen, the premature ingrowth of cells into the membrane body that are responsible for the degradation of collagen, such as macrophages, can be prevented. By preventing the ingrowth of these cell types, the standing time of collagen-based membranes could be prolonged. Interestingly, this approach has never been analyzed so far, thus there is no existing knowledge regarding the biocompatibility or the tissue integration behavior of such a material type.

It is known that nearly every biomaterial induces an inflammatory tissue reaction that is unique for the respective material, and depends on the combination of its physical and chemical properties (21). The tissue reaction to a biomaterial is a cascade that includes macrophages as a key element. The macrophages have been shown to be involved in the resorption of biodegradable biomaterials (29). In the case of natural collagen based materials, it has been assumed that macrophages are integrated into the "natural metabolism" process, together with fibroblasts and eosinophils (19). Thus, collagen materials that induce a tissue reaction involving the afore-mentioned mononuclear cell types, are assumed to be mostly biocompatible $(7,30)$. However, collagen materials can also induce a tissue response involving biomaterialassociated multinucleated giant cells (BMGCs) (31). It has been shown that BMGCs could be a foreign body giant cell type and their occurrence indicates a poor biomaterial biocompatibility (31). Finally, their induction can be associated with the premature breakdown of the barrier membrane and a loss of its functionality (32).

Macrophages (and also BMGCs) have been shown to express both pro- and anti-inflammatory molecules, depending on material factors such as surface topography or surface chemistry (33-35). Based on the expression of certain molecular markers, macrophages are more or less divided into pro-inflammatory $\mathrm{M} 1$ - and anti-inflammatory $\mathrm{M} 2$ subtypes $(36,37)$. Taken together, it is believed that the successful clinical application of a biomaterial has to be accompanied by an "overall M2 tissue reaction" to promote tissue healing, while a chronic pro-inflammatory M1 tissue response may lead to negative consequences for tissue remodeling, such as fibrous encapsulation $(36,37)$. Thus, the understanding of the material-specific foreign body reaction, and of the interactions of the immune system with a biomaterial is pivotal to ensure the safety, biocompatibility, and functionality of a medical device.

In the case of collagen-based biomaterials that are chemically processed such as the above-mentioned crosslinked barrier membranes, the native (ultra-) structure or molecular organization of collagen has changed. Therefore, the analysis of the cytocompatibility or biocompatibility, including the inflammatory tissue response, is of great importance to guarantee their successful clinical application. In contrast to cross-linked collagen, the newly developed condensation process only induces changes to the physical characteristics of the material and is thus intended to preserve the native molecular structure of collagen. By changing the physical properties of the material, such as the porosity, the cellular infiltration and the overall material degradation should be delayed.

The objective of the present study was to investigate a newly developed condensed collagen membrane for its material properties, ex vivo degradation, cytocompatibility and tissue integration, including the degradation processes and the material-induced inflammatory tissue reaction. A pericardium-based collagen membrane with an open-porous structure was used as a control material as its biocompatibility, tissue integration and functionality in the framework of GBR have been frequently analyzed in preclinical and clinical studies $(8,38)$. Established and published in vitro and in vivo methods were applied in this study $(32,39-42)$.

\section{Materials and Methods}

\section{Biomaterials}

Pericardium-based condensed collagen membrane. The analyzed condensed pericardium-based barrier membrane was made from porcine pericardium tissue that has been purified by manual and chemical treatment. The chemical treatment utilizes different acids 
and bases to purify the collagen matrix from other components of the extracellular matrix as well as from cells and their debris. The purified pericardium matrix finally undergoes condensation following a specialized technique using freeze drying (43). Finally, ethylene oxide gas sterilization was applied resulting in a transparent, condensed collagen structure.

Pericardium-based collagen membrane (Jason ${ }^{\circledR}$ membrane). The collagen membrane that was used as control in the present study is based on native collagen originating from porcine pericardium (Jason ${ }^{\circledR}$ membrane, botiss biomaterials, Zossen, Germany). The standardized manufacturing process includes an initial selection of the donor animals based on veterinary controls. During the purification process, the pericardium undergoes a wet-chemical treatment, lyophilization and sterilization by ethylene oxide gas. The collagen membrane exhibits a natural, multilayered structure with an increased content of collagen type III. Moreover, the membrane has been shown to fulfill the requirements of biocompatibility according to EN ISO 10993-1 and EN ISO 7405 (29).

\section{Ex vivo analyses}

Scanning electron microscopy (SEM). The (ultra-) structure of both biomaterials was imaged by scanning electron microscopy (SEM) using a XL30 CP SEM (Philips, Amsterdam, Netherlands).

Degradation assays. The analysis of the enzymatic degradation of the collagen membranes was carried out in phosphate buffered saline at $7.4 \mathrm{pH}$, using 50,100 , and $200 \mathrm{U} / \mathrm{ml}$ matrix metalloproteinase-1 (MMP-1) (Clostridium histolyticum, C0130 Sigma-Aldrich, St. Louis, MO, USA) for $24 \mathrm{~h}$ under static conditions and at physiological temperature $\left(37^{\circ} \mathrm{C}\right)$. The quantitative determination of the enzymatic degradation was conducted via sample weight that was recorded prior to enzymatic digestion and after $24 \mathrm{~h}$.

In vitro analyses. The in vitro cytocompatibility assays were accomplished according to EN ISO 10993-5/-12 regulations as previously described $(44,45)$. Extracts of all tested materials and the reference materials were initially prepared to conduct indirect biocompatibility analyses.

Briefly, L929-fibroblasts and MC3T3 pre-osteoblasts (European Collection of Cell Culture, ECACC, Salisbury, UK) were cultured in cell culture medium (Minimum Essential Medium, MEM) supplemented with $10 \%$ fetal bovine serum, penicillin/streptomycin (100 U/mL each) (all from Life Technologies, Carlsbad, CA, USA) and L-glutamine (Sigma-Aldrich) to a final concentration of $4 \mathrm{mM}$ and under standard cell culture conditions $\left(37^{\circ} \mathrm{C}, 5 \% \mathrm{CO}_{2}\right.$ and $95 \%$ humidity) up to $80 \%$ confluency before passaging. The standard control material RM-A (Hatano Research Institute, Food and Drug Safety Center, Kanagawa, Japan) was used as positive, toxic, control, while titanium grade 5 discs were used a negative, nontoxic control for biocompatibility. All materials were sterilized by hot-air sterilization.

Extracts of both collagen membranes and the above described reference materials dissolved in culture medium were added to 12 well cell culture plates at a surface-to-volume ratio of $3 \mathrm{~cm} 2 / \mathrm{ml}$ and incubated for $72 \mathrm{~h}$ under standard cell culture conditions. Cell culture medium alone was used as a medium control. Twenty-four hours before the end of incubation, the plates were seeded with $1 \times 10^{4} \mathrm{~L} 929$ cells/well in $100 \mu \mathrm{l}$ cell culture medium and incubated under standard cell culture conditions for $24 \mathrm{~h}$.
$B r d U, X T T$ and LDH assays. Test kits for analysis of the cytocompatibility and cell proliferation, i.e., XTT and BrdU kits (Roche Diagnostics, Mannheim, Germany), and the cytotoxicity, i.e., LDH assay (BioVision, Milpitas, CA, USA), were used according to the manufacturer's instructions as shown in previous studies (44-46). In brief, cells grown in 96-well plates were incubated with extracts from both membranes for $24 \mathrm{~h}$ before the XTT, BrdU and LDH assays were performed. Identically, extracts from both membranes not incubated with the cells were also used in the assays to subtract the background absorbance. The absorbance values of the controls were subtracted from the experimental absorbance values. Absorbances were measured with filters for 450 $\mathrm{nm}$ and 650 (XTT, LDH)/690 (BrdU) nm (reference wavelength).

Live-Dead-staining. For Live-Dead-staining, extracts from both membranes and the reference materials were seeded with $2.4 \times 10^{5}$ L929 cells in $1 \mathrm{ml}$ cell culture medium under standard culture conditions in 12-well cell culture plates. The ratio of the surface area to medium was adjusted to $5.65 \mathrm{~cm}^{2} / \mathrm{ml}$. After $24 \mathrm{~h}, 60 \mu \mathrm{l} / \mathrm{ml}$ propidium iodide (PI) stock solution $(50 \mu \mathrm{g} / \mathrm{ml}$ in PBS) and 500 $\mu \mathrm{l}$ per $\mathrm{ml}$ fresh fluorescein diacetate $(20 \mu \mathrm{g} / \mathrm{ml}$ in PBS from 5 $\mathrm{mg} / \mathrm{ml}$ FDA in acetone stock solution) were added to each well for $3 \min 21^{\circ} \mathrm{C}$. Subsequently, the test samples were rinsed in prewarmed PBS and examined under an upright fluorescence microscope (Nikon ECLIPSE Ti-S/L100, Nikon GmbH, Düsseldorf, Germany) equipped with a filter for parallel detection of red and green fluorescence. Pictures were taken at $4 \times, 10 \times$ and $20 \times$ magnification.

\section{In vivo analysis}

Study design, subcutaneous implantation and explantation procedure. The in vivo study was conducted as previously described by Barbeck et al. (41). In brief, the experiments and the animal housing were performed at the Faculty of Medicine of the University of Niš (Serbia). After approval through the Local Ethical Committee on the basis of the regulations of the Veterinary Directorate of the Ministry of Agriculture, Forestry and Water Management of the Republic of Serbia (decision number: 323-0700278/2017-05/6, date: 13/07/2017), the animals were kept under standard conditions (water ad libitum, artificial light and regular rat pellet).

In total, 40 female, 6-8 week-old BALB/c mice obtained from the Military Medical Academy (Belgrade, Serbia) were randomly allocated into two study groups. Each of the two study groups contained 20 experimental animals and 5 animals were used for implantation of the respective biomaterial per time point $(n=5)$, i.e., $10,30,60$ and 90 days. The implantation was conducted following the protocol described by Barbeck et al. (24-26, 28, 30). Initially, the animals were anesthetized via an intraperitoneal injection of 10 $\mathrm{ml}$ ketamine $(50 \mathrm{mg} / \mathrm{ml})$ and $1.6 \mathrm{ml}$ xylazine $(2 \%)$ and their dorsal skin within the subscapular region was shaved and disinfected. Subsequently, an incision down to the subcutaneous tissue was made and a subcutaneous pocket was bluntly built by a scissor, in which the biomaterials were implanted. Afterwards, the wounds were sutured. Standard pre- and postoperative care was ensured. At the respective study time points the animals were euthanized with an overdose of the above-mentioned anesthetics and the implantation area together with the surrounding peri-implant tissue was explanted and fixed using a $4 \%$ formalin solution for $24 \mathrm{~h}$ for the following histological analyses. 

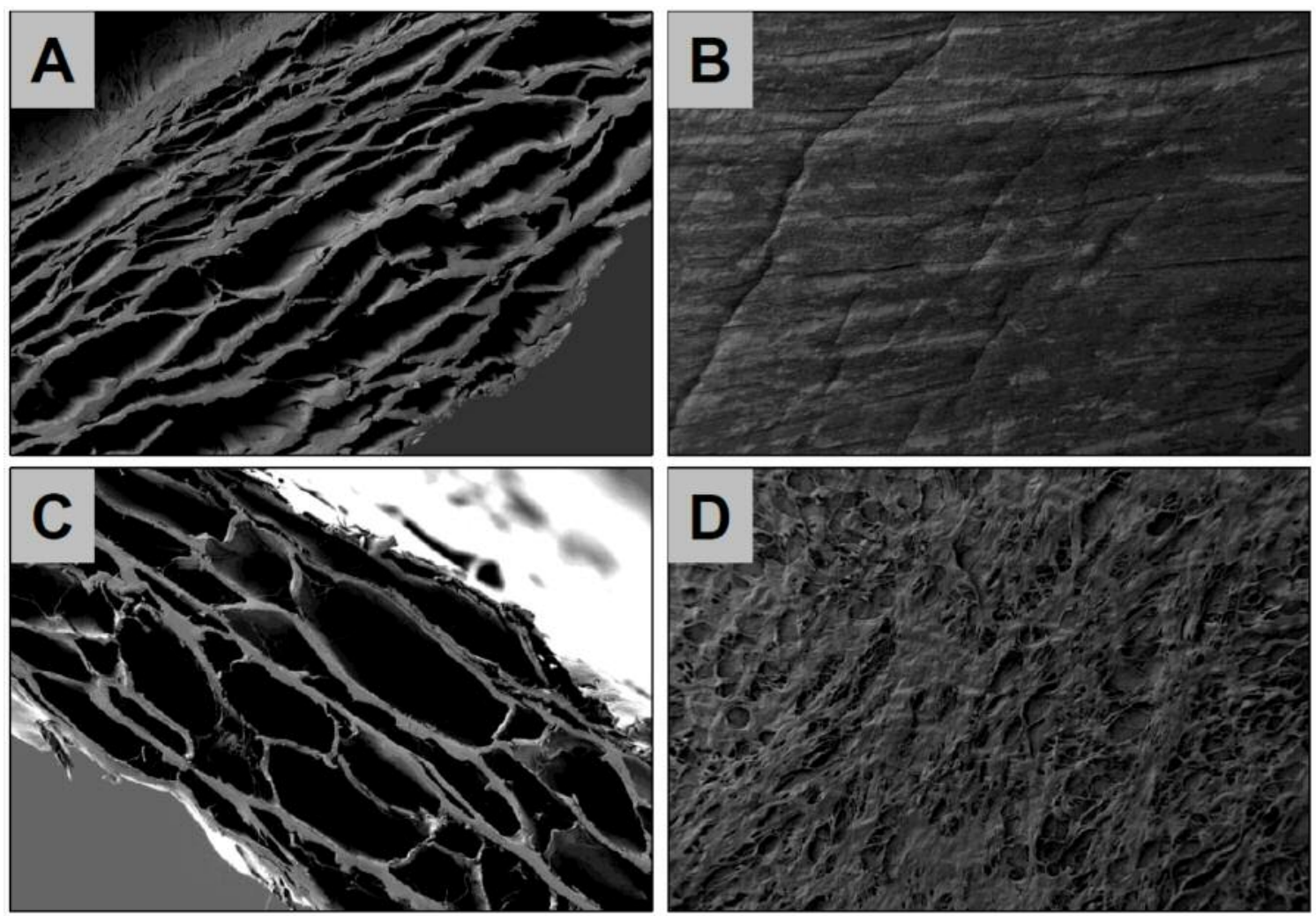

Figure 1. Exemplary scanning electron microscopy (SEM) images of the analyzed pericardium-based collagen membranes. (A) Cross section and (B) surface pattern of the newly developed pericardium-based barrier membrane. (C) Cross section and (D) surface pattern of a commercially available and commonly used pericardium-based collagen membrane (Jason ${ }^{\circledR}$ membrane) (A and C: 20x magnification, B and D: 100x magnification).

Histology and immunohistochemistry. The tissue explants containing the membrane pieces were initially cut into two segments of identical dimensions and dehydrated using a series of increasing alcohol concentrations followed by a xylol exposure. Afterwards, paraffin embedding was performed for preparing sections with a thickness of 3-5 $\mu \mathrm{m}$ by means of a rotation microtome (SLEE, Mainz, Germany). Three sections of every tissue explant were used for histochemical staining, i.e., haematoxylin and eosin (H\&E) and Alcian blue.

Furthermore, four additional sections of every tissue explant were used for immunohistochemical detection of macrophages and their M1- and M2-subtypes by means of antibodies against pro- and antiinflammatory molecules, i.e., hemoglobin scavenger receptor (CD163) and mannose receptor (MR, also known as CD206) based on previously published methods $(28,30-32)$. Briefly, the slides were initially treated with citrate buffer and proteinase $\mathrm{K}$ at $\mathrm{pH} 8$ for $20 \mathrm{~min}$ in a water bath at $96^{\circ} \mathrm{C}$ followed by equilibration using TBS-T buffer. Subsequently, the slides were treated with $\mathrm{H}_{2} \mathrm{O}_{2}$ and avidin and biotin blocking solutions (Avidin/Biotin Blocking Kit, Vector Laboratories, Burlingame, CA, USA). Incubation with the respective first antibody for $30 \mathrm{~min}$ was conducted followed by incubation with the secondary antibody (goat anti- rabbit IgG-B, sc2040, 1:200, Santa Cruz Biotechnology, Dallas, TX, USA). Afterwards, the avidin-biotin-peroxidase complex (ThermoFisher Scientific, Waltham, MA, USA) (30 min) was applied and a counterstaining by hematoxylin was conducted.
Histological analysis. The histological analyses to study the tissuebiomaterial-interactions within the implantation beds of the membranes and their surrounding tissue were conducted using an Axio.Scope.A1 microscope (Zeiss, Oberkochen, Germany) as previously established by Barbeck et al. $(32,39-42)$. These analyses focused on the evaluation of the following parameters within the framework of the early and the late tissue response related to the biomaterials: fibrosis, hemorrhage, necrosis, vascularization and the presence of neutrophils, lymphocytes, plasma cells, macrophages, biomaterial-associated multinucleated giant cells (BMGCs). Finally, microphotographs were taken with an Axiocam 305 color connected to a computer system running the ZEN Core software (Zeiss, Oberkochen, Germany) connected to the microscope.

Histomorphometrical analysis. The histomorphometrical analyses included the comparative measurements of the occurrence of antiinflammatory and pro-inflammatory macrophages within the implant beds of the membranes as previously described (24-28). Briefly, "total scans" were generated with the aid of a specialized scanning microscope consisting of an Axio.Scope.A1 microscope combined with an Axiocam 305 color digital camera and an automatic scanning table (Maerzhaeuser, Wetzlar, Germany) connected to a computer system running the ZEN Core software (all: Zeiss, Oberkochen, Germany). The resulting images contained the complete implant area as well as the peri-implant tissue. The 
slides stained by the afore mentioned immunohistochemical methods were digitized and both the total implant area as well as the extents of the inflammatory cells within the respective implantation beds were manually measured. Finally, the numbers of these cells were related to the total implant area (cells $\left./ \mathrm{mm}^{2}\right)$.

Statistical analyses. The measurement data were analyzed by analysis of variance (ANOVA), which enabled comparison of the data from the study groups using the GraphPad Prism 7.0d software (GraphPad Software Inc., La Jolla, USA). Inter- $\left(^{*}\right)$ and intraindividual $(\bullet)$ statistical differences were designated as significant if $p$-values were less than $0.05(* / * p \leq 0.05)$, and highly significant if $p$-values were less than $0.01(* * / \bullet \bullet \leq 0.01)$ or less than 0.001 $(* * * / \bullet \bullet p \leq 0.001)$. Finally, the data were graphed as mean \pm standard deviation.

\section{Results}

Results of the ex vivo analyses. Ex vivo analysis performed using scanning electron microscopy (SEM) showed that the newly developed compacted pericardium-based collagen membrane has a porous structure with small pores (Figure 1A). The SEM analysis additionally showed that the collagenous fiber structure was preserved after the condensation process (Figure 1A). Moreover, a thin collagen layer was found at the outer surface of the membrane, which produced a non-porous and smooth surface pattern (Figure $1 \mathrm{~A}$ and $\mathrm{B})$. In contrast, the conventional collagen membrane, which is also based on pericardium tissue, showed a porous structure with larger pores (Figure 1D). It also showed the preservation of the collagenous matrix fibers with a porous surface pattern (Figure 1C and D).

The ex vivo degradation analysis of the newly developed compacted membrane did not reveal any significant differences between the two tested membranes (Figure 2). A mean degradation rate of $2.29 \pm 0.62 \%$ was measured for the PM, which was only slightly lower compared to the values for the CPM $(0.62 \pm 0.19 \%)$ (Figure 2). Furthermore, only minor differences were found after conducting a collagenase degradation assay (Figure 2). A mean degradation rate of $19.96 \pm 3.59 \%$ was detected in the PM group and of $17.65 \pm 0.63 \%$ in the CPM group (Figure 2).

Results of the in vitro analyses. Analyses of the cytocompatibility (XTT), cell proliferation (BrdU) and the cytotoxicity (LDH) were conducted. Additionally, LiveDead-stainings were conducted to visualize the interaction of cells with the membranes and the control materials. In this context, the negative, non-toxic control materials (titanium grade 5 disks) and the positive, toxic control materials (RMA disks) were used to define both the limits of the biocompatibility (non-toxic range of $>70 \%$ ) in the XTT and BrdU assays and the $130 \%$ threshold for cytotoxicity in the LDH assays in accordance to the respective ISO norm (47). Thus, it is expected that the negative, non-toxic control

\section{In vitro degradation}

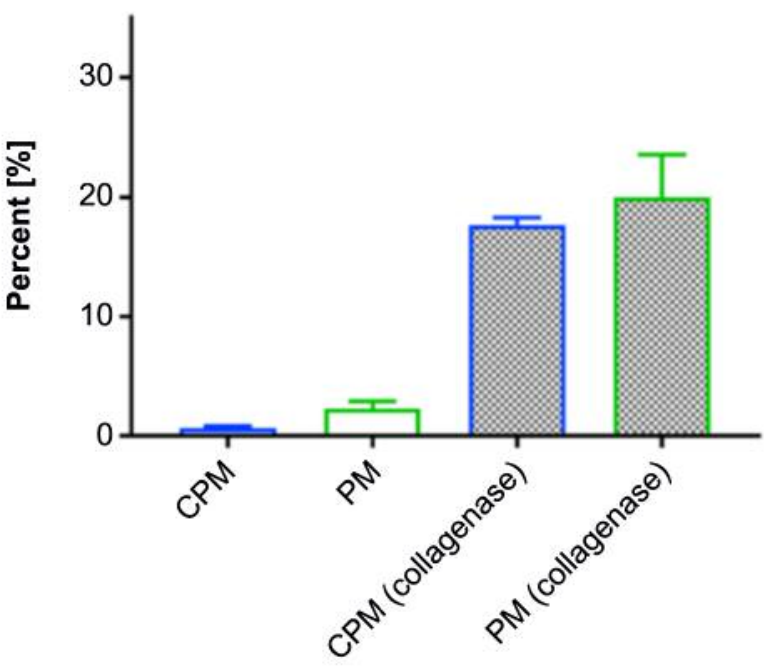

Figure 2. The results of the ex vivo degradation analyses of both pericardium-based membranes without (graphs on the left side) and with collagenase (graphs on the right side, hatched bars). The analysis without collagenases represent the degradation behavior within tissue fluids, while the analysis including collagenases mainly represents the cellular material degradation.

material shows high levels of cytocompatibility and promotes proliferation in the XTT and BrdU assays above $70 \%$, while the positive, toxic control material shows high levels of cytotoxicity in the LDH assays above $130 \%$. Furthermore, it is expected that the positive, toxic control materials show low levels of cytocompatibility and proliferation in the XTT and BrdU assays below $70 \%$.

In the XTT assays for analysis of the cytocompatibility using both L929 fibroblasts and MC3T3 osteoblasts, the values in the both membrane groups and the negative control group were significantly higher compared to the values in the positive control group $(* * * p<0.001)$ (Figure 3A and B). Moreover, the values in the both membrane groups were comparable, while they were significantly lower compared to the values in the negative control group $(* * p<0.01$ and $* * * p<0.001$ ) (Figure 3A and B).

In the BrdU assay for analysis of the cell proliferation using both cell lines, the values in the both membrane groups and the negative control group were significantly higher compared to the values in the positive control group $(* * * p<0.001)$ (Figure 3C and D). Furthermore, the values in both membrane groups were comparable in both cell lines, while they were only significantly lower in the case of the MC3T3 osteoblasts compared to the values in the negative control group $(* * * p<0.001)$ (Figure 3D). In contrast, no significant differences were found between the values in both membrane groups and that in the negative control group (Figure 3C). 

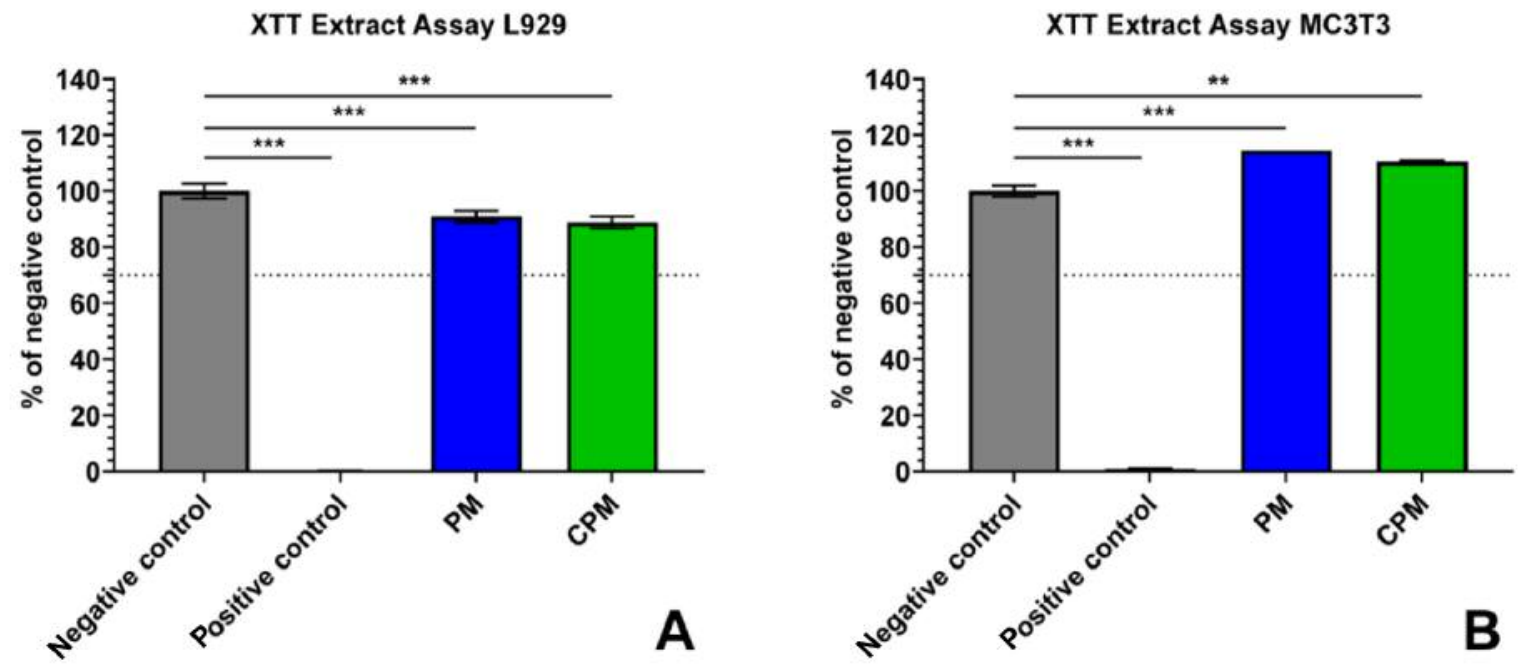

BrdU Extract Assay L929

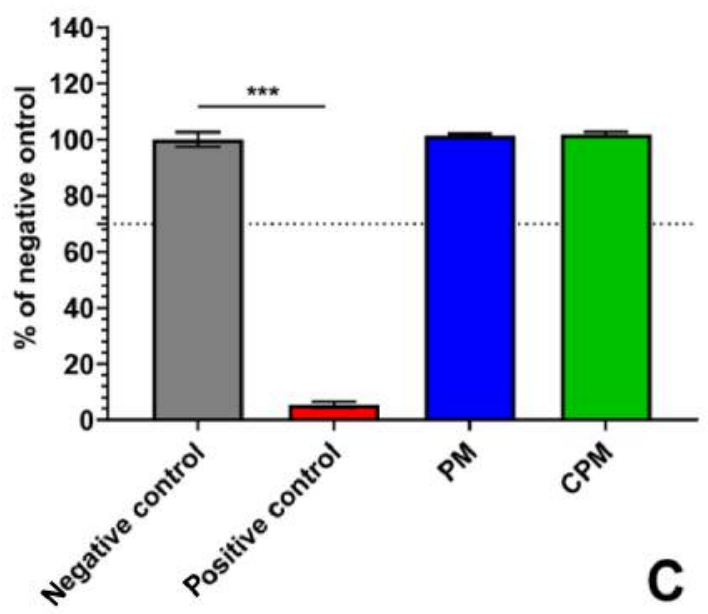

BrdU Extract Assay MC3T3

LDH Extract Assay L929

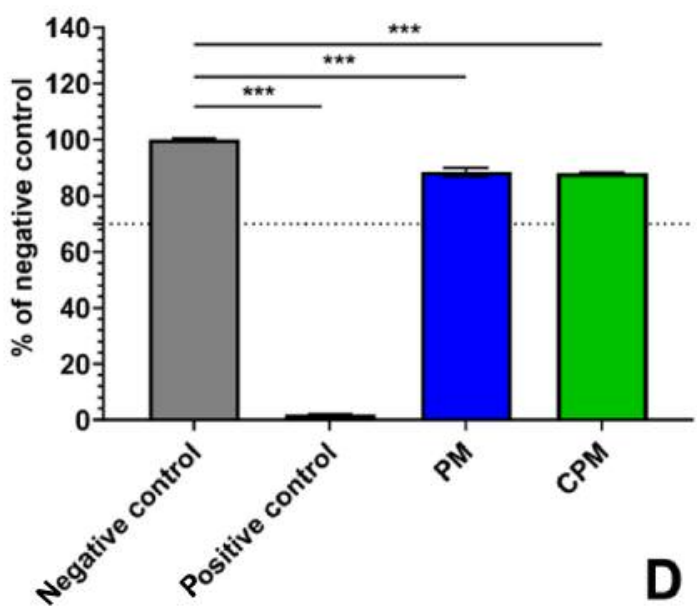

LDH Extract Assay MC3T3
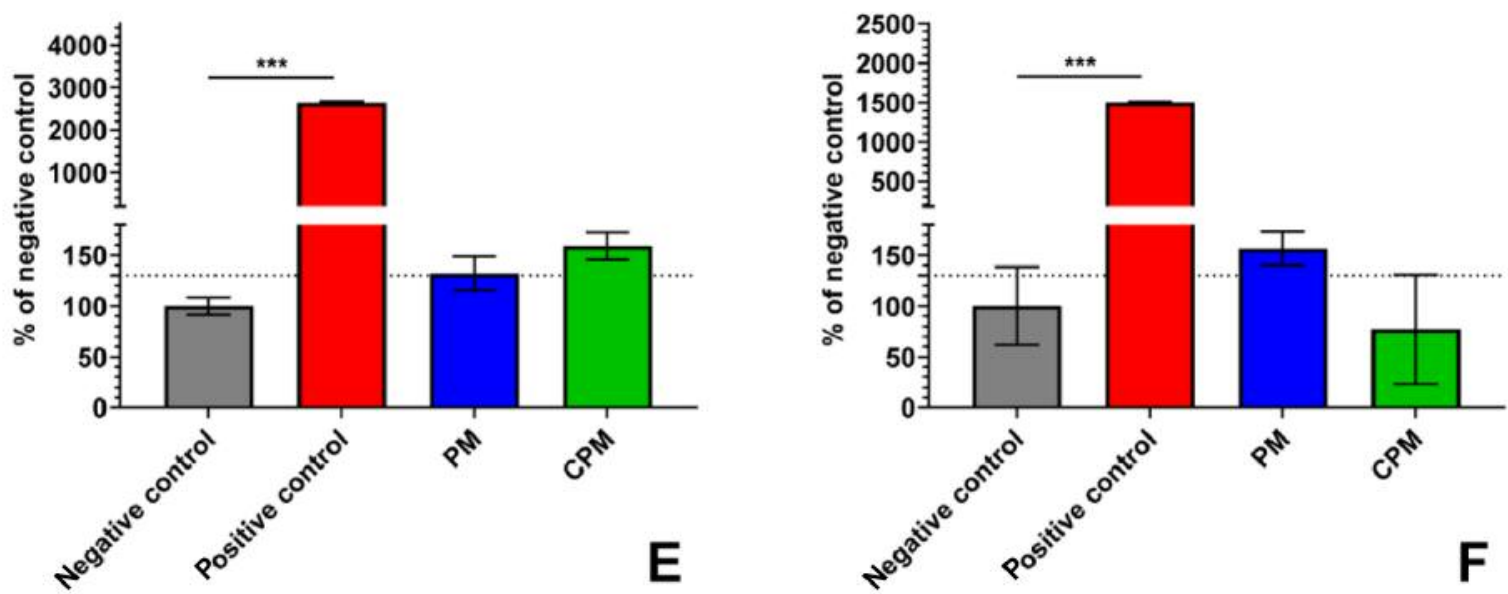

Figure 3. Cytocompatibility analyses of the condensed pericardium membrane (CPM) as experimental group and conventional pericardium membrane (PM) as the control material group. in vitro analyses of the cytocompatibility (XTT), cell proliferation (BrdU) and the cytotoxicity (LDH) were conducted using two cell lines, i.e., L929 fibroblasts (left column) and MC3T3 osteoblasts (right column). Titanium grade 4 (negative nontoxic control) and RM-A (positive toxic control) were used as control materials. Significance levels were as follows: **p<0.01 and $* * * p<0.001$. 


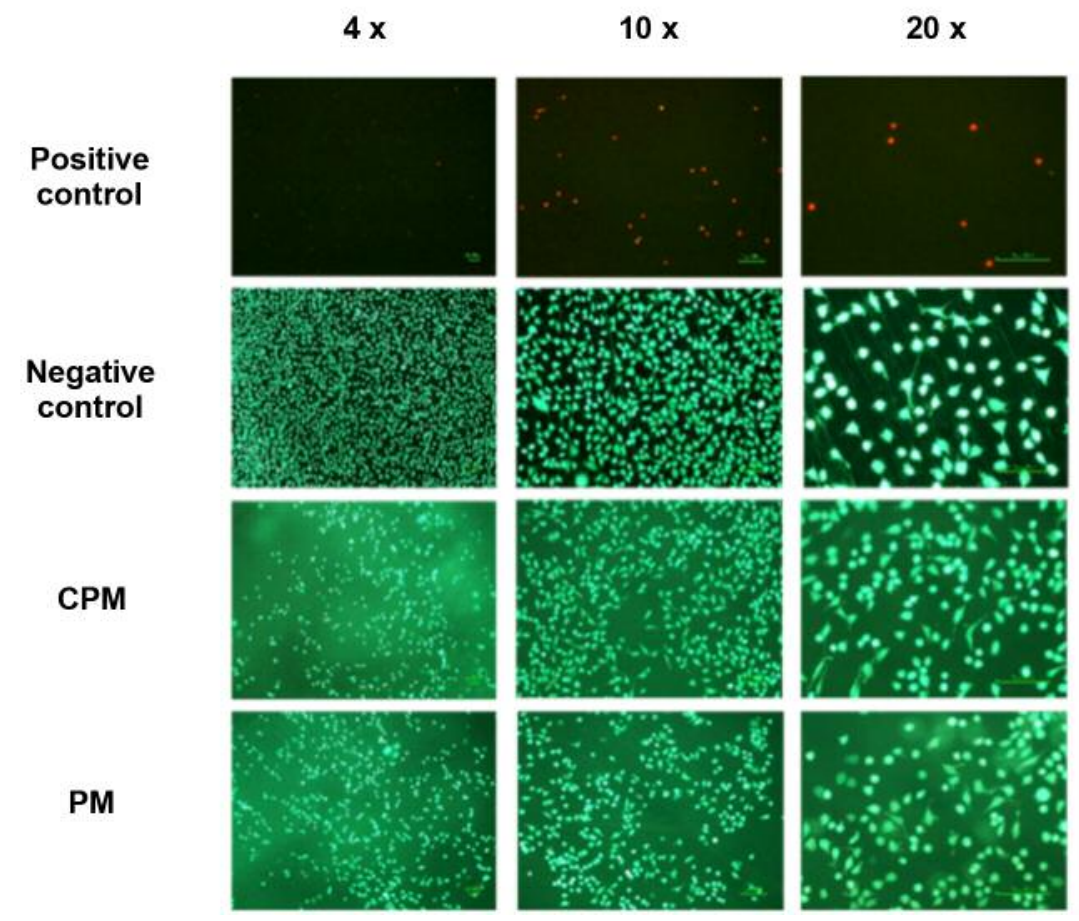

Figure 4. Live-Dead-staining of L929 fibroblasts on the both collagen membranes and the both control materials. Green fluorescence indicates viable cells while red fluorescence indicates dead cells. Spindle-shaped cells illustrate attachment on the surface of the materials, while a rounded cell morphology demonstrates poor attachment to the surface. Both materials exhibited viable green fluorescent and the cells attached, similar to the negative control. On the positive, toxic control, mainly dead cells were visible.

In the LDH assay for analysis of the cytotoxicity using L929 fibroblasts and MC3T3 osteoblasts, the values in the positive control group were significantly higher compared to the values in the both membrane groups and the negative control group (Figure 3E and F). Moreover, the values in the negative control groups of both cell types were below the $130 \%$ threshold for cytotoxicity (Figure 3E and F). The values in the both membrane groups exceeded the $130 \%$ threshold for cytotoxicity in case of the L929 fibroblasts without significant differences between the values in both groups (Figure 3E). Using MC3T3 osteoblasts, the condensed collagen membrane was within the non-toxic range, while the native pericardium membrane exceeded the $130 \%$ threshold for cytotoxicity (Figure 3F).

The analysis using Live-Dead-staining revealed that almost exclusively green, viable and spindle-shaped attached cells were found on the surfaces of the both collagen membrane types and the negative control materials (Figure 4). On the surfaces of the positive control, only a few rounded dead red cells were visible (Figure 4).

Taken together, our results showed that both membranes exhibited a suitable level of cytocompatibility within the non-toxic range of $>70 \%$ compared to the negative control using L929 and MC3T3 cells, according to the EN ISO 10993:5:2009 norm using the XTT and the BrdU assays.
Furthermore, only the condensed collagen membrane was within the non-toxic range using MC3T3 osteoblasts in the LDH assays. Additionally, both the CPM and PM demonstrated satisfying cytocompatibility values comparable to the negative control materials using the Live-Deadstaining.

Results of the in vivo analyses.

Results of the histopathological analysis. Histopathological analysis showed that the compacted pericardium-based collagen membrane was detectable within the subcutaneous connective tissue at day 10 post implantation. The CPM was surrounded by a cell-rich layer containing macrophages, granulocytes and single fibroblasts, with no ingrowth of cells into the membrane body (Figure 5A). Especially at the material surface, a layer of macrophages was identified at this early study time point (Figure 5A). In the PM control group, a cell-rich layer composed mainly of macrophages, granulocytes as well as a few fibroblasts was detected at day 10 post implantation within the implantation beds (Figure 5B). In contrast to the CPM, the ingrowth of a moderate number of cells was observed within the superficial regions of the membrane body, while the material centers were free of invading cells (Figure 5B). The immunohistochemical detection of M1- and M2-macrophages showed a comparably 

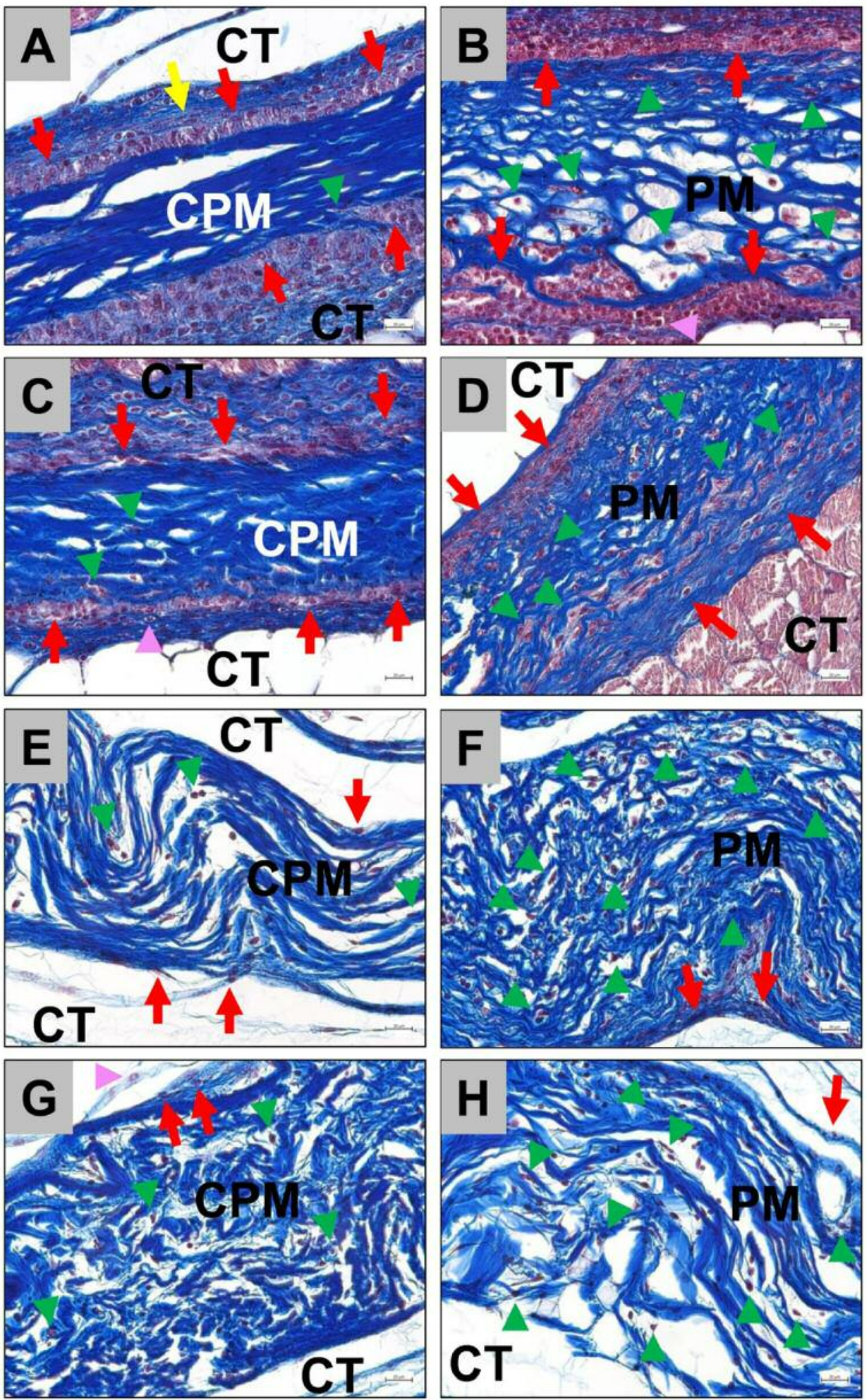

Figure 5. Representative microscopic images of the compacted pericardium-based barrier membrane (CPM) and the pericardium-based control membrane (PM) implanted in the subcutaneous connective tissue (CT) (red arrows: macrophages located at the outer material surfaces, green arrowheads: cells within the material bodies, yellow arrow: fibroblasts, pink arrowheads: granulocytes) (Alcian Blue-staining's, 400x magnification, scale bars $=20 \mu \mathrm{m})$. 


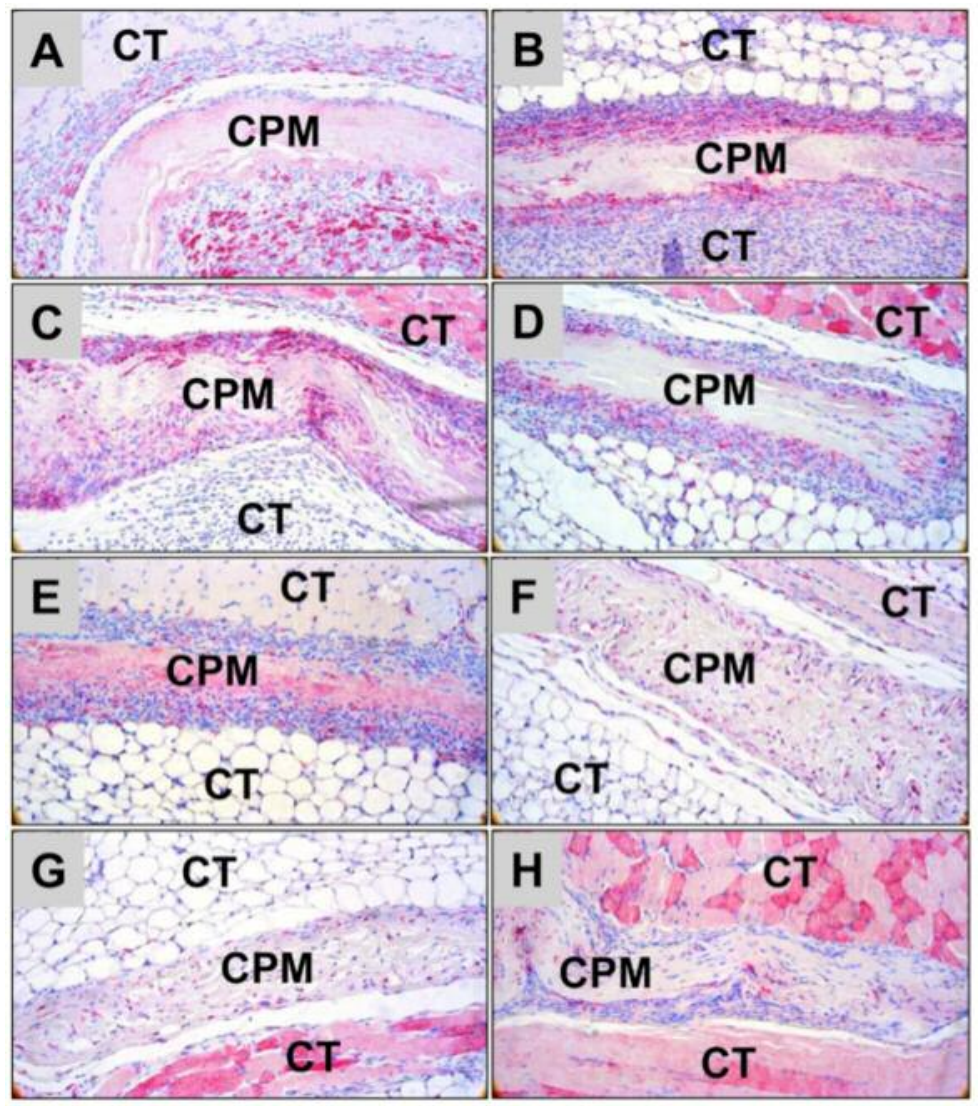

Figure 6. Representative microscopic images of M1- (left column) and M2- (right column) macrophage responses to the compacted pericardiumbased barrier membrane $(C P M)$ at day $10(A$ and $B)$, day $30(C$ and $D)$, day $60(E$ and $F)$ and day $90(G$ and $H)$ implanted in the subcutaneous connective tissue (CT) (red staining=macrophages) (CD163- and CD206-immunostainings, 200x magnification).

high number of both M1 and M2 macrophages in the implantation beds of both membranes, although a slightly higher number of M2 macrophages were found in the CPM group (Figure 6 and 7A and B). In contrast, higher numbers of M1 macrophages were present in the group of the native collagen membrane (Figure 6 and 7A and B).

At day 30 post implantation, the membranes were detectable within their implantation beds. The CPM had a cell-rich layer mainly composed of macrophages, singular granulocytes and fibroblasts on its surface (Figure 5C). At this time point, only singular cells had invaded the membrane's body, while most of the cells were located near the material surface (Figure 5C). Around the surface of the control membranes, a layer composed mainly of macrophages was detected, whilst the membrane body was nearly completely invaded by macrophages without any signs of fragmentation or loss of barrier functionality (Figure 5D). Moreover, the immunohistochemical detection of macrophage subtypes revealed comparably high numbers of pro- and antiinflammatory macrophages within the implantation beds of both biomaterials (Figure 6 and 7C and D). However, there was a trend towards a higher number of M1 macrophages involved in tissue reaction for the PM group (Figure 6 and $7 \mathrm{C}$ and D).

At day 60 post implantation, the tissue reactions in both study groups had completely changed (Figure 5E and F). Both membranes were still visible within the subcutaneous connective tissue without any material-related tissue reactions at their surfaces (Figure 5E and F). At this time point, the membrane bodies of both biomaterials contained cells that were mainly macrophages (Figure 5E and F). However, visibly lower numbers of cells had invaded the compacted CPMs, while higher numbers were found within the material bodies of the PMs (Figure 5E and F). The histological analysis of the macrophage response showed a comparably high number of M1 and M2 macrophages detectable in both study groups, whilst a higher number of M1 macrophages were still present in the PM group (Figure 6 and $7 \mathrm{E}$ and F).

After 90 days post implantation, both membranes were still detectable within the connective tissue without any sign of breakdown or loss of barrier functionality (Figure 5G and $\mathrm{H})$. Moreover, no signs of material-related inflammatory tissue reactions were observed. Interestingly, the histological 


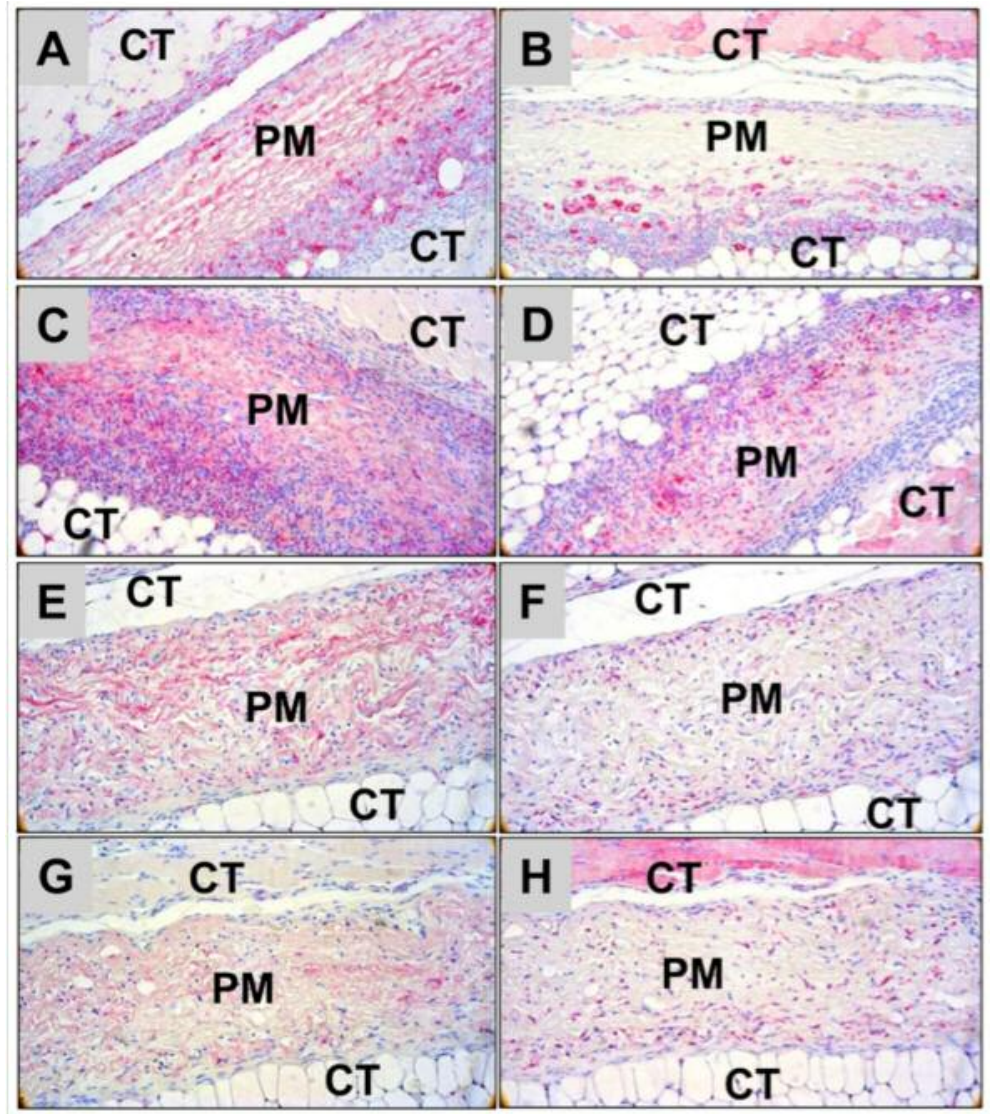

Figure 7. Representative microscopic images of the M1- (left column) and M2- (right column) macrophage responses to the native pericardiumbased barrier membrane (PM) at day 10 ( $A$ and B), day $30(C$ and $D)$, day 60 (E and F) and day 90 ( $G$ and $H)$ implanted in the subcutaneous connective tissue $(C T)$ (red staining=macrophages) (CD163- and CD206-immunostainings, 200 $\times$ magnification).

appearance was similar to the results at day 30 after implantation: only singular cells of the macrophage line were found within the bodies of the compacted pericardium-based collagen membranes, with higher numbers of macrophages found within the bodies of the PMs (Figure 5G and $\mathrm{H}$ ). Moreover, the histological analysis showed that control membranes seemed to have undergone a higher extent of degradation compared to the compacted membranes, which did not show any signs of degradation (Figure 5G and $\mathrm{H}$ ). At this last time point, the immunohistochemical detection of macrophage subtypes showed similar numbers of pro- and anti-inflammatory macrophages in the implantation beds of both membranes (Figure 6 and $7 \mathrm{G}$ and $\mathrm{H}$ ). In both study groups, the numbers of M1 macrophages seemed to be slightly higher compared to the numbers of M2 macrophages (Figure 6 and $7 \mathrm{G}$ and $\mathrm{H}$ ).

Results of the histomorphometrical analysis. The histomorphometrical analysis for the occurrence of biomaterialinduced macrophages and their pro- and anti-inflammatory subtypes, showed that comparable numbers of both subtypes were detected in the implantation beds of both membrane types without significant differences between the different time points (Table I and Figure 6). However, tendencies of pro- or anti-inflammatory tissue responses were observable (Figure 6). An anti-inflammatory macrophage response was slightly higher at day 10 post implantation in the case of CPM, while at this early study time point the proinflammatory macrophage response was predominant in the case of PM (Table I and Figure 6).

At day 30 post implantation, no differences between the numbers of pro-inflammatory CD206-positive macrophages were observed, with a tendency for a higher antiinflammatory tissue response in the CPM group compared to the PM group (Table I and Figure 6).

At day 60 post implantation no differences between the numbers of pro- and anti-inflammatory macrophages in the CPM group were found. In the PM group, a mild tendency towards a pro-inflammatory tissue response was measured (Table I and Figure 6). 
Table I. Results of the histomorphometrical measurements of the occurrence of biomaterial-induced M1- and M2-macrophages (cells/mm²).

\begin{tabular}{clll}
\hline \multirow{4}{*}{10 days } & \multicolumn{1}{c}{ CPM } & \multicolumn{1}{c}{ PM } \\
\hline \multirow{4}{*}{30 days } & CD163 & $792.9 \pm 385.5$ & $409.9 \pm 253.1$ \\
& CD206 & $512.8 \pm 187.1$ & $818.9 \pm 300.1$ \\
& CD163 & $500.3 \pm 346.7$ & $179.7 \pm 51.11$ \\
& CD206 & $466.9 \pm 221.7$ & $472.9 \pm 158.1$ \\
\multirow{2}{*}{90 days days } & CD163 & $170.7 \pm 149.4$ & $87.05 \pm 36.4$ \\
& CD206 & $171.2 \pm 100.1$ & $272.9 \pm 39.58$ \\
& CD163 & $135.4 \pm 69.47$ & $101.7 \pm 50.69$ \\
& CD206 & $506.6 \pm 110.2$ & $382.1 \pm 112.8$ \\
\hline
\end{tabular}

At day 90 post implantation in both study groups, a tendency towards a preponderance of a pro-inflammatory macrophage response due to higher numbers of CD206positive macrophages was detected, while comparably lower numbers of CD163-positive macrophages were measured (Table I and Figure 6).

Only intraindividual differences regarding the numbers of anti-inflammatory macrophages were found between day 10 and day 60 , as well as day 90 post implantation $\left({ }^{\bullet \bullet} p<0.001\right)$ in the CPM group (Figure 6). In contrast, significant decreases of pro-inflammatory macrophages were found in the PM group between day 10 and day 60, as well as day 90 post implantation $\left({ }^{\bullet} p<0.05\right.$ and ${ }^{\bullet \bullet} p<0.01$ ) (Figure 6).

\section{Discussion}

A potential disadvantage of barrier membranes based on native collagen is their relatively short standing time, since native collagen is rapidly degraded by tissue-specific proteases, collagenases and different cell types such as macrophages $(24,48,49)$. Moreover, different preclinical in vivo studies have shown that different collagen membranes induce different inflammatory tissue reactions. These can include induction of a biomaterial-associated multinucleated giant cell (BMGC) response that can be associated with premature breakdown of the barrier membrane and loss of its functionality (32). When natural collagen materials demonstrate only biocompatible properties, they are assumed to provide optimal integration into the surrounding tissue via a "natural metabolism processes" (19). This is a tissue reaction involving mononuclear cell types such as fibroblasts, macrophages and eosinophils (14).

A variety of materials have already been analyzed to prolong the standing time of collagen-based barrier membranes $(25,50)$. Most prominently, cross-linking has been tested in different studies, but has shown to lead to unintended inflammatory tissue reactions involving BMGCs $(22,26)$. Condensation of pericardium collagen is an

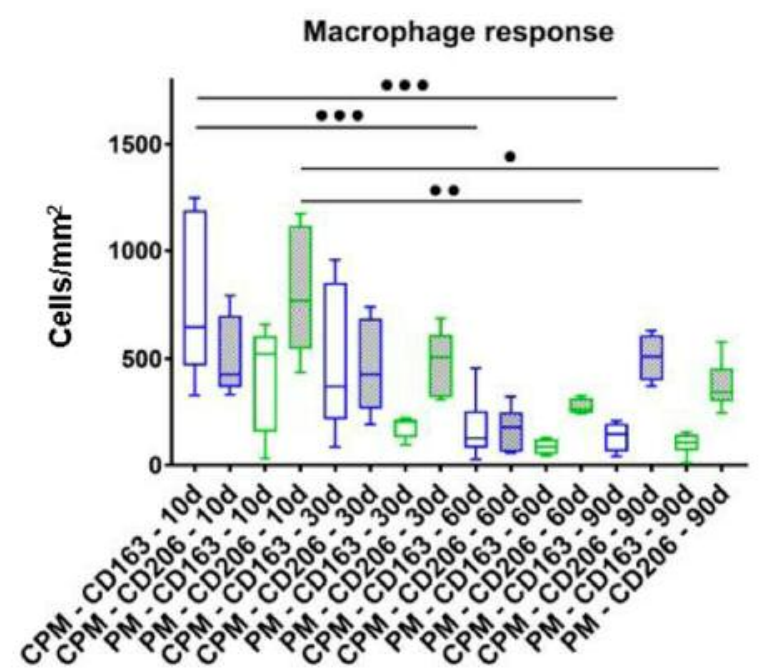

Figure 8. Results of the degradation analyses of both pericardium-based membranes with and without collagenase (intraindividual differences: $\bullet p<0.05,{ }^{\bullet \bullet} p<0.01$ and $\left.{ }^{\bullet \bullet} p<0.001\right)$.

alternative method of improving the functional life span of collagen. It has been assumed that collagen condensation may prevent premature ingrowth of degrading cells and prolong the standing time of a collagen-based barrier membrane. Thus, the present study used specialized and previously published in vitro and in vivo methods to evaluate the biocompatibility of the newly developed collagen membrane. The in vitro study included standardized analysis methods for cytocompatibility using L929 and MC3T3 cells according to EN:ISO 10993-5/-12 regulations (45). The in vivo study included a standardized analysis of the tissue reactions and biocompatibility using well established methods $(32,39,41)$.

The understanding of the material-specific foreign body reaction, and of the interactions of the immune system with a biomaterial is pivotal to ensure the safety, biocompatibility, and functionality of a medical device. For this reason, the immune response to a new condensed collagen barrier membrane was investigated using published histopathological and histomorphometrical methods of analysis, which mainly focus on the immunohistochemical detection of CD163- and CD206-positive macrophages $(32,39-42)$. An existing native pericardium-based collagen membrane was used as a control as it has established and well described biocompatible and resorbable properties $(8,38)$.

The results of the SEM analysis initially showed that the (ultra-) structure of the original tissue has been preserved in both the condensed collagen membrane and the native pericardium membrane. However, the condensation procedure impacted the porous structure since the pores, i.e., the interfibrillar spaces, were much smaller in the CPM. This 
result is of great interest as it has been shown that not only chemical properties, but also physical material factors such the porosity, have major effects on the tissue integration of biomaterials (51), although most of these studies were investigating the integration of bone substitute materials (39, 40). It has been shown by Doernberg and colleagues that the material resorption of membranes with large pores was higher than those with smaller pores (52). Moreover, it has been shown that the integration of materials with bigger pore sizes resulted in higher soft tissue content (52). Thus, it is assumed that a smaller pore size prevents cell or tissue ingrowth and can prolong the standing time of the new barrier membrane.

The ex vivo degradation analysis showed that there were no differences to the degradation pattern of the newly developed CPM compared to the degradation pattern of the PM, with and without collagenase. These data lead to two further conclusions: first, there does not seem to be any differences in the chemical composition of both analyzed membranes, which could have caused differences in the degradation pattern. Thus, both membranes exhibit only minimal degradation in aqueous solution and, more importantly, have similar interactions with the collagenase used for this assay. Second, the condensation process did not influence the surface area of the new membrane, as reported in the case of different bone substitutes with varying (micro-) porosities (39). A comparable surface area for both membranes also means that both materials underwent a comparable percentage of weight loss, as neither membrane possessed a higher contact surface area to interact with degrading molecules, such as collagenases. Altogether, the presented ex vitro data leads to the conclusion that only physical material characteristics, and mainly the pore size, were changed by the newly developed condensation process.

The results of the in vitro study showed that both analyzed membranes provide comparable and good cytocompatibility, as all measured values indicate that cells can grow onto both biomaterials. In particular, the data revealed that both membranes showed similar results that exceeded the $70 \%$ threshold for cytocompatibility in both viability and proliferations assays. In the toxicity assay, both materials slightly transcended the toxic range with L929-cells while not being significantly different from the reference material. In the LDH assay using MC3T3 cells, only PM slightly exceeded the toxic range. These data are in line with different studies conducted by Rothamel et al. that have also shown a good biocompatibility of the control membrane (Jason membrane) $(8,31,53,54)$. Based on these results, it can be concluded that the newly developed condensed collagen barrier membrane provides an excellent biocompatibility. Thus, the condensation process does not have any influence onto the cytocompatibility of the newly developed membrane.
The histological results show that the newly developed collagen membrane induces a tissue reaction based only on mononuclear cells, which indicates that the new biomaterial is degraded via physiological processes in agreement with the results of Ghanaati (7). This author analyzed the tissue reactions to one of the most commonly applied GBR membranes sourced from bovine dermis. It was found that the degradation of the native collagen membrane is mediated via fibroblasts, macrophages and eosinophils and stated that this resorption mechanism reflects full biocompatibility. Based on this former description, it is concluded that the analyzed condensed collagen membrane provides an excellent biocompatibility in combination with prolonged cellular infiltration. This makes the new membrane favorable for GBR procedures, even in the case of larger jawbone defects when compared to the membrane analyzed by Ghanaati, which was degraded in 12-16 weeks $(7,19)$. However, this assumption is still uncertain, and further preclinical in vivo and clinical studies must demonstrate the standing time of this newly developed membrane type.

Interestingly, the in vivo results revealed that the native collagen membrane used as a control induced a comparable tissue reaction without the occurrence of multinucleated giant cells within 90 days after implantation. This result leads to two conclusions: first, this native collagen membrane is a completely biocompatible biomaterial (8). Based on the presented results, the newly developed collagen membrane can also be considered to be comparably biocompatible. Second, the tissue reactions to the membrane involved multinucleated giant cells that lead to a premature fragmentation of the membrane, hence a loss of its functionality (55). In contrast, the results presented in this study showed that the native membrane is integrated within the connective tissue without any signs of a foreign body reaction. These new results lead to the question of the comparability of different implantation models and the tissue reactions to biomaterials in different experimental animals and tissues.

The histomorphometrical analysis of the pro- and antiinflammatory macrophage subtypes showed a comparable number of both subtypes without significant differences at all study times points between the implantation beds of the condensed collagen barrier membrane and the control group. However, tendencies were observed comparing the tissue responses to both membrane types. At day 10 after implantation, a dominant anti-inflammatory macrophage reaction was observed in the CPM group in contrast to a more pro-inflammatory macrophage reaction in the group of the control membrane. At day 30 post implantation, still no differences between the numbers of pro-inflammatory macrophages were detected in both study groups, while a tendency of a higher pro-inflammatory tissue response in the PM group was still detectable. At day 60 and 90 post implantation, only a tendency towards a more pro- 
inflammatory tissue reaction was found in both study groups.

These results are very interesting as the overall data shows that the inflammatory tissue reactions to both biomaterials are comparable. Thus, these results again underline the biocompatibility of the newly developed condensed barrier membrane even in comparison to the native collagen membrane. Moreover, the above-mentioned tendencies in the early tissue reaction are of interest as an early high number of pro-inflammatory macrophages is generally expected within the implantation bed of a biomaterial due to the to the implantation process and related reactions to a tissue defect $(36,37)$. This inflammatory alignment has been observed in the case of the control membrane, but the data shows that the CPM induced a higher anti-inflammatory tissue response at an earlier time point. Although this reaction pattern is not underpinned by significance, the reason for this phenomenon is questionable. Both materials are based on the same precursor tissue, i.e., pericardium tissue, and only differ in the condensation step in the case of the new barrier membrane. In this context, it has been described by different authors that the physical properties of a biomaterial can also influence the integration pattern and the tissue reaction as in the case of different bone substitute materials $(8,56,57)$.

Thus, it is possible that the material properties of the condensed collagen membrane lead to an altered pattern of the inflammatory tissue response. However, it should be critically noted, that in this context, the results of the present study can only provide limited information on the degree of the inflammatory reaction, as the immunohistochemical investigation method does not allow any statement on the degree of expression of the various cytokines or mediators by macrophages involved in the inflammatory tissue reaction. Thus, the immunohistochemical detection method is not an analytical method that allows an accurate quantification of the severity of the foreign body reaction to the biomaterials, although it is an initial indicator that provides an insight into the general tissue reaction to a biomaterial. This leads to the conclusion that a standardized in vitro test system with the cell types involved in the foreign body reaction to a biomaterial may also be necessary for biocompatibility analysis to prevent the introduction of insufficient biomaterials. In addition, specialized in vivo analysis methods, such as laser-assisted cell microdissection, which enables the measurement of cytokine release from single cells or cell types, are important tools for biomaterial research and development $(58,59)$. The entire tissue reaction to a biomaterial should therefore be seen as a dynamic process. Thus, the reaction of the peri-implant tissue can increase or decrease over time without leading to a foreign body reaction with encapsulation.

Overall, the results of the present study showed that the tissue reaction to the new condensed collagen barrier membrane includes only mononuclear cells, like inflammatory macrophages and granulocytes. Moreover, comparable cell numbers were found in the peri-implant tissue of a well-established membrane. Based on these data, it can be assumed that the newly developed pericardium collagen membrane provides sufficient biocompatibility and an extended lifetime and barrier function up to a period of 90 days. This opens new possibilities for bone healing in the context of guided bone regeneration.

\section{Conclusion}

The results of the present study show that the newly developed condensed barrier membrane is fully biocompatible and seems to support the early healing process. Moreover, the new biomaterial seems to prevent cell ingrowth for longer time periods making it ideal for GBR procedures, even in cases of large defects of the jaws.

\section{Funding}

This research received no external funding.

\section{Conflicts of Interest}

The Authors declare no conflict of interest regarding this study.

\section{Authors' Contributions}

Conceptualization, M.B. and A.H.; methodology, M.B.; formal analysis, T.G.; investigation, T.G.; resources, M.B.; data curation, M.B. and T.G..; writing-original draft preparation, T.G., M.B. and O.J.; writing-review and editing, S.N., M.R., T.K., M.G. and R.S.; visualization, T.G. and M.B..; supervision, M.G. and R.S.; project administration, M.B.; funding acquisition, M.B..

\section{Acknowledgements}

The Authors would like to thank Ms. Anne-Kathrin Kopp for her excellent technical assistance and Mr. Torsten Müller for his excellent organization support.

\section{References}

1 Beretta M, Cicciu M, Poli PP, Rancitelli D, Bassi G, Grossi GB and Maiorana C: A retrospective evaluation of 192 implants placed in augmented bone: Long-term follow-up study. J Oral Implantol 41(6): 669-674, 2015. PMID: 25686360. DOI: 10.1563/aaid-joi-D-14-00123

2 Lang NP, Hammerle CH, Bragger U, Lehmann B and Nyman SR: Guided tissue regeneration in jawbone defects prior to implant placement. Clin Oral Implants Res 5(2): 92-97, 1994. PMID: 7918914. DOI: 10.1034/j.1600-0501.1994.050205.x

3 Oh TJ, Meraw SJ, Lee EJ, Giannobile WV and Wang HL: Comparative analysis of collagen membranes for the treatment of implant dehiscence defects. Clin Oral Implants Res 14(1): 8090, 2003. PMID: 12562369. DOI: 10.1034/j.1600-0501.2003. 140111.x 
4 Burkhardt R and Lang NP: Role of flap tension in primary wound closure of mucoperiosteal flaps: A prospective cohort study. Clin Oral Implants Res 21(1): 50-54, 2010. PMID: 20070747. DOI: 10.1111/j.1600-0501.2009.01829.x

5 McAllister BS and Haghighat K: Bone augmentation techniques. J Periodontol 78(3): 377-396, 2007. PMID: 17335361. DOI: 10.1902/jop.2007.060048

6 Barbeck M, Lorenz J, Kubesch A, Bohm N, Booms P, Choukroun J, Sader R, Kirkpatrick CJ and Ghanaati S: Porcine dermis-derived collagen membranes induce implantation bed vascularization via multinucleated giant cells: A physiological reaction? J Oral Implantol 41(6): e238-251, 2015. PMID: 25546240. DOI: 10.1563/aaid-joi-D-14-00274

7 Ghanaati S: Non-cross-linked porcine-based collagen i-iii membranes do not require high vascularization rates for their integration within the implantation bed: A paradigm shift. Acta Biomater 8(8): 3061-3072, 2012. PMID: 22561669. DOI: 10.1016/j.actbio.2012.04.041

8 Rothamel D, Schwarz F, Fienitz T, Smeets R, Dreiseidler T, Ritter L, Happe A and Zoller J: Biocompatibility and biodegradation of a native porcine pericardium membrane: Results of in vitro and in vivo examinations. Int $\mathrm{J}$ Oral Maxillofac Implants 27(1): 146-154, 2012. PMID: 22299091.

9 Postlethwaite AE, Seyer JM and Kang AH: Chemotactic attraction of human fibroblasts to type I, II, and III collagens and collagen-derived peptides. Proc Natl Acad Sci U S A 75(2): 871875,1978

10 Locci P, Calvitti M, Belcastro S, Pugliese M, Guerra M, Marinucci L, Staffolani N and Becchetti E: Phenotype expression of gingival fibroblasts cultured on membranes used in guided tissue regeneration. J Periodontol 68(9): 857-863, 1997. PMID: 204938. DOI: 10.1073/pnas.75.2.871

11 Schlegel AK, Mohler H, Busch F and Mehl A: Preclinical and clinical studies of a collagen membrane (bio-gide). Biomaterials 18(7): 535-538, 1997. PMID: 9105592. DOI: 10.1016/s01429612(96)00175-5

12 Rothamel D, Schwarz F, Sculean A, Herten M, Scherbaum W and Becker J: Biocompatibility of various collagen membranes in cultures of human pdl fibroblasts and human osteoblast-like cells. Clin Oral Implants Res 15(4): 443-449, 2004. PMID: 15248879. DOI: 10.1111/j.1600-0501.2004.01039.x

13 Pitaru S, Tal H, Soldinger M and Noff M: Collagen membranes prevent apical migration of epithelium and support new connective tissue attachment during periodontal wound healing in dogs. J Periodontal Res 24(4): 247-253, 1989. PMID: 2528624. DOI: 10.1111/j.1600-0765.1989.tb01789.x

14 Behring J, Junker R, Walboomers XF, Chessnut B and Jansen JA: Toward guided tissue and bone regeneration: Morphology, attachment, proliferation, and migration of cells cultured on collagen barrier membranes. A systematic review. Odontology 96(1): 1-11, 2008. PMID: 18661198. DOI: 10.1007/s10266-008$0087-\mathrm{y}$

15 Bornstein MM, Bosshardt D and Buser D: Effect of two different bioabsorbable collagen membranes on guided bone regeneration: A comparative histomorphometric study in the dog mandible. J Periodontol 78(10): 1943-1953, 2007. PMID: 18062116. DOI: $10.1902 /$ jop.2007.070102

16 Bunyaratavej P and Wang HL: Collagen membranes: A review. J Periodontol 72(2): 215-229, 2001. PMID: 11288796. DOI: 10.1902/jop.2001.72.2.215
17 Chattopadhyay S and Raines RT: Review collagen-based biomaterials for wound healing. Biopolymers 101(8): 821-833, 2014. PMID: 24633807. DOI: 10.1002/bip.22486

18 Jardelino C, Takamori ER, Hermida LF, Lenharo A, Castro S, II and Granjeiro JM: Porcine peritoneum as source of biocompatible collagen in mice. Acta Cir Bras 25(4): 332-336, 2010. PMID: 20676490. DOI: $10.1590 / \mathrm{s} 0102-86502010000400006$

19 Owens KW and Yukna RA: Collagen membrane resorption in dogs: A comparative study. Implant Dent 10(1): 49-58, 2001. PMID: 11307648. DOI: 10.1097/00008505-200101000-00016

20 Machtei EE: The effect of membrane exposure on the outcome of regenerative procedures in humans: A meta-analysis. J Periodontol 72(4): 512-516, 2001. PMID: 11338304. DOI: 10.1902/jop.2001.72.4.512

21 Tal H, Kozlovsky A, Artzi Z, Nemcovsky CE and Moses O: Cross-linked and non-cross-linked collagen barrier membranes disintegrate following surgical exposure to the oral environment: A histological study in the cat. Clin Oral Implants Res 19(8): 760-766, 2008. PMID: 18720556. DOI: 10.1111/j.16000501.2008.01546.x

22 Tal H, Kozlovsky A, Artzi Z, Nemcovsky CE and Moses O: Long-term bio-degradation of cross-linked and non-cross-linked collagen barriers in human guided bone regeneration. Clin Oral Implants Res 19(3): 295-302, 2008. PMID: 18190562. DOI: 10.1111/j.1600-0501.2007.01424.x

23 Retzepi M and Donos N: Guided bone regeneration: Biological principle and therapeutic applications. Clin Oral Implants Res 21(6): 567-576, 2010. PMID: 20666785. DOI: 10.1111/j.16000501.2010.01922.x

24 Dimitriou R, Mataliotakis GI, Calori GM and Giannoudis PV: The role of barrier membranes for guided bone regeneration and restoration of large bone defects: Current experimental and clinical evidence. BMC Med 10: 81, 2012. PMID: 22834465. DOI: $10.1186 / 1741-7015-10-81$

25 Rothamel D, Schwarz F, Sager M, Herten M, Sculean A and Becker J: Biodegradation of differently cross-linked collagen membranes: An experimental study in the rat. Clin Oral Implants Res 16(3): 369-378, 2005. PMID: 15877758. DOI: 10.1111/ j.1600-0501.2005.01108.x

26 Speer DP, Chvapil M, Eskelson CD and Ulreich J: Biological effects of residual glutaraldehyde in glutaraldehyde-tanned collagen biomaterials. J Biomed Mater Res 14(6): 753-764, 1980. PMID: 6820019. DOI: 10.1002/jbm.820140607

27 Shim JH, Won JY, Park JH, Bae JH, Ahn G, Kim CH, Lim DH, Cho DW, Yun WS, Bae EB, Jeong CM and Huh JB: Effects of 3d-printed polycaprolactone/beta-tricalcium phosphate membranes on guided bone regeneration. Int J Mol Sci 18(5), 2017. PMID: 28441338. DOI: 10.3390/ijms18050899

28 Lin D-J, Hung F-Y, Lee H-P and Yeh M-L: Development of a novel degradation-controlled magnesium-based regeneration membrane for future guided bone regeneration (gbr) therapy. Metals 7(11): 481, 2017. DOI: 10.3390/met7110481

29 Korzinskas T, Jung O, Smeets R, Stojanovic S, Najman S, Glenske K, Hahn M, Wenisch S, Schnettler R and Barbeck M: In vivo analysis of the biocompatibility and macrophage response of a non-resorbable ptfe membrane for guided bone regeneration. In: Int j mol sci. 2018. PMID: 30262765. DOI: 10.3390/ijms 19102952

30 Moura CC, Soares PB, Carneiro KF, Souza MA and Magalhaes D: Cytotoxicity of bovine and porcine collagen membranes in 
mononuclear cells. Braz Dent J 23(1): 39-44, 2012. PMID: 22460313. DOI: $10.1590 / \mathrm{s} 0103-64402012000100007$

31 Rothamel D, Benner M, Fienitz T, Happe A, Kreppel M, Nickenig HJ and Zoller JE: Biodegradation pattern and tissue integration of native and cross-linked porcine collagen soft tissue augmentation matrices - an experimental study in the rat. Head Face Med 10: 10, 2014. PMID: 24670219. DOI: 10.1186/1746160X-10-10

32 Barbeck M, Udeabor SE, Lorenz J, Kubesch A, Choukroun J, Sader RA, Kirkpatrick CJ and Ghanaati S: Induction of multinucleated giant cells in response to small sized bovine bone substitute (bio-oss) results in an enhanced early implantation bed vascularization. Ann Maxillofac Surg 4(2): 150-157, 2014 PMID: 25593863. DOI: 10.4103/2231-0746.147106

33 Lamichhane S, Anderson JA, Vierhout T, Remund T, Sun H and Kelly P: Polytetrafluoroethylene topographies determine the adhesion, activation, and foreign body giant cell formation of macrophages. J Biomed Mater Res A 105(9): 2441-2450, 2017. PMID: 28466979. DOI: 10.1002/jbm.a.36099

34 Jones JA, Chang DT, Meyerson H, Colton E, Kwon IK, Matsuda $\mathrm{T}$ and Anderson JM: Proteomic analysis and quantification of cytokines and chemokines from biomaterial surface-adherent macrophages and foreign body giant cells. J Biomed Mater Res A 83(3): 585-596, 2007. PMID: 17503526. DOI: 10.1002/ jbm.a.31221

35 Brodbeck WG, Nakayama Y, Matsuda T, Colton E, Ziats NP and Anderson JM: Biomaterial surface chemistry dictates adherent monocyte/macrophage cytokine expression in vitro. Cytokine 18(6): 311-319, 2002. PMID: 12160519. DOI: 10.1006/ cyto. 2002.1048

36 Brown BN, Valentin JE, Stewart-Akers AM, McCabe GP and Badylak SF: Macrophage phenotype and remodeling outcomes in response to biologic scaffolds with and without a cellular component. Biomaterials 30(8): 1482-1491, 2009. PMID: 19121538. DOI: $10.1016 /$ j.biomaterials 2008.11 .040

37 Badylak SF, Valentin JE, Ravindra AK, McCabe GP and Stewart-Akers AM: Macrophage phenotype as a determinant of biologic scaffold remodeling. Tissue Eng Part A 14(11): 18351842, 2008. PMID: 18950271. DOI: 10.1089/ten.tea.2007.0264

38 Rothamel D, Schwarz F, Smeets R, Happe A, Fienitz T, Mazor $\mathrm{Z}$ and Zöller J: Sinus floor elevation using a sintered, natural bone mineral. JDI 01/2011, 2011.

39 Barbeck M, Dard M, Kokkinopoulou M, Markl J, Booms P, Sader RA, Kirkpatrick CJ and Ghanaati S: Small-sized granules of biphasic bone substitutes support fast implant bed vascularization. Biomatter 5(e1056943, 2015. PMID: 26083163. DOI: $10.1080 / 21592535.2015 .1056943$

40 Barbeck M, Unger RE, Booms P, Dohle E, Sader RA, Kirkpatrick CJ and Ghanaati S: Monocyte preseeding leads to an increased implant bed vascularization of biphasic calcium phosphate bone substitutes via vessel maturation. J Biomed Mater Res A 104(12): 2928-2935, 2016. PMID: 27419378. DOI: 10.1002/jbm.a.35834

41 Barbeck M, Serra T, Booms P, Stojanovic S, Najman S, Engel E, Sader R, Kirkpatrick CJ, Navarro M and Ghanaati S: Analysis of the in vitro degradation and the in vivo tissue response to bi-layered 3d-printed scaffolds combining pla and biphasic pla/bioglass components - guidance of the inflammatory response as basis for osteochondral regeneration. Bioact Mater 2(4): 208-223, 2017. PMID: 29744431. DOI: 10.1016/j.bioactmat.2017.06.001
42 Tawil G, Barbeck M, Unger R, Tawil P and Witte F: Sinus floor elevation using the lateral approach and window repositioning and a xenogeneic bone substitute as a grafting material: A histologic, histomorphometric, and radiographic analysis. Int $\mathbf{J}$ Oral Maxillofac Implants 33(5): 1089-1096, 2018. PMID: 29894551. DOI: $10.11607 /$ jomi.6226

43 Yunoki S, Ikoma T and Tanaka J: Development of collagen condensation method to improve mechanical strength of tissue engineering scaffolds. Materials Characterization 61(9): 907-911, 2010. DOI: $10.1016 /$ j.matchar.2010.05.010

44 Jung O, Smeets R, Porchetta D, Kopp A, Ptock C, Muller U, Heiland M, Schwade M, Behr B, Kroger N, Kluwe L, Hanken $\mathrm{H}$ and Hartjen P: Optimized in vitro procedure for assessing the cytocompatibility of magnesium-based biomaterials. Acta Biomater 23: 354-363, 2015. PMID: 26073090. DOI: 10.1016/ j.actbio.2015.06.005

45 Jung O, Smeets R, Hartjen P, Schnettler R, Feyerabend F, Klein M, Wegner N, Walther F, Stangier D, Henningsen A, Rendenbach $\mathrm{C}$, Heiland M, Barbeck M and Kopp A: Improved in vitro test procedure for full assessment of the cytocompatibility of degradable magnesium based on iso 10993-5/-12. Int J Mol Sci 20(2), 2019. PMID: 30634646. DOI: 10.3390/ijms20020255

46 Jung O, Smeets R, Kopp A, Porchetta D, Hiester P, Heiland M, Friedrich RE, Precht C, Hanken H, Grobe A and Hartjen P: Peogenerated surfaces support attachment and growth of cells in vitro with no additional benefit for micro-roughness in sa (0.24 mum). In Vivo 30(1): 27-33, 2016. PMID: 26709125

47 Din en iso 10993-5 - 2009-10. Biological evaluation of medical devices - part 5: Tests for in vitro cytotoxicity. 2019(23.04.2019), 2010.

48 Bozkurt A, Apel C, Sellhaus B, van Neerven S, Wessing B, Hilgers RD and Pallua N: Differences in degradation behavior of two non-cross-linked collagen barrier membranes: An in vitro and in vivo study. Clin Oral Implants Res 25(12): 1403-1411, 2014. PMID: 25539007. DOI: 10.1111/clr.12284

49 Stoecklin-Wasmer C, Rutjes AW, da Costa BR, Salvi GE, Juni P and Sculean A: Absorbable collagen membranes for periodontal regeneration: A systematic review. J Dent Res 92(9): 773-781, 2013. PMID: 23842107. DOI: $10.1177 / 0022034513496428$

50 von Arx T, Broggini N, Jensen SS, Bornstein MM, Schenk RK and Buser D: Membrane durability and tissue response of different bioresorbable barrier membranes: A histologic study in the rabbit calvarium. Int J Oral Maxillofac Implants 20(6): 843853, 2005. PMID: 16392340.

51 Zellin G and Linde A: Effects of different osteopromotive membrane porosities on experimental bone neogenesis in rats. Biomaterials 17(7): 695-702, 1996. PMID: 8672631. DOI: 10.1016/0142-9612(96)86739-1

52 von Doernberg MC, von Rechenberg B, Bohner M, Grunenfelder S, van Lenthe GH, Muller R, Gasser B, Mathys R, Baroud $\mathrm{G}$ and Auer J: In vivo behavior of calcium phosphate scaffolds with four different pore sizes. Biomaterials 27(30): 5186-5198, 2006. PMID: 16790273. DOI: 10.1016/j. biomaterials.2006.05.051

53 Scheer M, Ritter L, Dreiseidler T, Lingohr T, Mischkowski RA and Zöller JE: Surface morphology, biocompatibility and osseous organization of a new biphasic bone substitute (maxresorb ${ }^{\circledR}$ ). A combined in-vitro/in-vivo analysis. 2019.

54 Rothamel D TR, Neugebauer J, Fienitz T, Scheer M, Kreppel M, Mischkowski R and Zöller J: Clinical aspects of novel types of 
collagen membranes and matrices: Current issues in soft- and hard- tissue augmentation. EDI J 1/2012: 62, 2012.

55 Barbeck M, Booms P, Unger R, Hoffmann V, Sader R, Kirkpatrick CJ and Ghanaati S: Multinucleated giant cells in the implant bed of bone substitutes are foreign body giant cells-new insights into the material-mediated healing process. J Biomed Mater Res A 105(4): 1105-1111, 2017. PMID: 28093892. DOI: 10.1002/jbm.a.36006

56 Schenk RK, Buser D, Hardwick WR and Dahlin C: Healing pattern of bone regeneration in membrane-protected defects: A histologic study in the canine mandible. Int J Oral Maxillofac Implants 9(1): 13-29, 1994. PMID: 8150509.

57 Schwarz F, Rothamel D, Herten M, Sager M and Becker J: Angiogenesis pattern of native and cross-linked collagen membranes: An immunohistochemical study in the rat. Clin Oral Implants Res 17(4): 403-409, 2006. PMID: 16907771. DOI: 10.1111/j.1600-0501.2005.01225.x
58 Micke P, Ostman A, Lundeberg J and Ponten F: Laser-assisted cell microdissection using the palm system. Meth Mol Biol 293: 151-166, 2005. PMID: 16028418. DOI: 10.1385/1-59259-8536:151

59 Fink L, Kinfe T, Stein MM, Ermert L, Hanze J, Kummer W, Seeger W and Bohle RM: Immunostaining and laser-assisted cell picking for mrna analysis. Lab Invest 80(3): 327-333, 2000. PMID: 10744068. DOI: 10.1038/labinvest.3780037

Received January 27, 2020

Revised February 18, 2020

Accepted February 25, 2020 